\title{
Análise perceptivo-auditiva vocal na síndrome gripal ocasionada pelo SARS-CoV-2: série de casos
}

\author{
Vocal auditory-perceptual analysis in the flu-like syndrome caused by SARS-CoV-2: case series \\ Análisis auditivo-perceptivo de la voz en la síndrome gripal causada por SARS-CoV-2: serie de
}

casos

Recebido: 01/11/2021 | Revisado: 08/11/2021 | Aceito: 11/11/2021 | Publicado: 16/11/2021

Carla Patrícia Hernandez Alves Ribeiro César
ORCID: https://orcid.org/0000-0002-9439-9352
Universidade Federal de Sergipe, Brasil
E-mail: carlacesar@academico.ufs.br
Lucileide dos Santos
Fonoaudióloga Clínica, Brasil
E-mail: lusafga @ gmail.com
ORCID: https://orcid.org/000-000-4580-541
Ariane Damasceno Pellicani
ORCID: https://orcid.org/0000-0003-0390-9175
Universidade Federal de Sergipe, Brasil
E-mail: ariane.pellicani.ap@ gmail.com
Nathália Monteiro Santos
ORCID: https://orcid.org/0000-0003-2746-5361
Universidade Federal de Sergipe, Brasil
E-mail: nathaliamonteiro.fono@ gmail.com
Roxane de Alencar Irineu
ORCID: https://orcid.org/0000-0002-0614-4772
Universidade Federal de Sergipe, Brasil
E-mail: roxaneirineu@gmail.com

\section{Resumo}

A síndrome gripal ocasionada pelo novo coronavírus acarreta manifestações clínicas das vias aéreas respiratórias tanto superiores quanto inferiores, que podem impactar a produção vocal. Objetivo: Descrever as alterações vocais produzidas pela síndrome gripal ocasionada pelo SARS-CoV-2, nos momentos durante e após a cura da doença. Metodologia: Estudo retrospectivo, constituído por amostra de conveniência de quatro casos clínicos (um com diagnóstico clínico e outros três com diagnóstico laboratorial de COVID-19), de sujeitos entre 56 e 81 anos de vida, sendo três do sexo feminino e um do masculino, em que amostras de fala espontânea foram obtidas por meio de mídia social e realizada a análise perceptivo-auditiva vocal. A pesquisa foi aprovada pelo comitê de ética. Resultados: As manifestações vocais comuns durante a infecção foram pitch mais grave, loudness ligeiramente mais fraco no início da infecção, incoordenação pneumofonoarticulatória, presença de soprosidade, tensão e flutuação na qualidade vocal, além da queixa de dificuldade para manter-se com um padrão de normalidade respiratória o que repercutiu na eficiência glótica. Conclusão: Os parâmetros vocais demonstraram-se alterados nos casos clínicos relatados com SAR-CoV-2, sendo importante que os profissionais da saúde fiquem atentos também à essa possibilidade para identificação e atuação terapêutica de forma que, com aumento do número de amostras possa ser discutido se as alterações vocais podem ou não serem inseridas nos protocolos de identificação e reabilitação da COVID-19.

Palavras-chave: Infecções por Coronavírus; COVID-19; Virus da SARS; Voz; Fonoaudiologia.

\begin{abstract}
The flu-like syndrome caused by the new coronavirus creates clinical manifestations of both upper and lower respiratory airways, which can impact the vocal production. Objective: To describe the vocal changes produced by the flu syndrome caused by SARS-CoV-2 during and after the cure of the disease. Methodology: Retrospective study, consisting of a convenience sample of four clinical cases (one with a clinical diagnosis and the other three with a laboratory diagnosis of COVID-19), of subjects between 56 and 81 years of age, three female and one male, in which samples of spontaneous speech were obtained through a social media application and a vocal perceptual-auditory analysis was performed. The research was approved by the ethics committee. Results: The common vocal manifestations during the infection presented lower pitch, slightly weaker loudness at the beginning of the infection, pneumophonoarticulatory incoordination, presence of breathiness, tension and fluctuation in the vocal quality, in addition to the complaint of difficulty in maintaining a pattern of respiratory normality which reflected in glottic
\end{abstract}


efficiency. Conclusion: The vocal parameters were altered in the clinical cases reported with SAR-CoV-2, and health professionals must be also aware of this possibility for identification and therapeutic action so that with an increase number of samples can make possible further discussions on whether or not vocal changes can be included in the COVID-19 identification and rehabilitation protocols.

Keywords: Coronavirus infections; COVID-19; SARS virus; Voice; Speech, language and hearing sciences.

\section{Resumen}

El síndrome de gripe causada por el nuevo coronavirus causa manifestaciones clínicas tanto de las vías respiratorias superiores como inferiores, que pueden afectar la producción vocal. Objetivo: Describir las alteraciones vocales producidas por el síndrome gripal causado por el SARS-CoV-2, en momentos durante y después de la curación de la enfermedad. Metodología: Estudio retrospectivo, consistente en una muestra de conveniencia de cuatro casos clínicos (uno con diagnóstico clínico y otros tres con diagnóstico de laboratorio de COVID-19), de sujetos entre 56 y 81 años, tres mujeres y un hombre, en cuyas muestras de habla espontánea se obtuvieron a través de las redes sociales y se realizó el análisis vocal auditivo-perceptivo. La investigación fue aprobada por el comité de ética. Resultados: Las manifestaciones vocales comunes durante la infección fueron tono más bajo, sonoridad levemente más débil al inicio de la infección, incoordinación neumophonoarticulatory, presencia de respiración, tensión y fluctuación en la calidad vocal, además de la queja de dificultad para mantener un patrón respiratorio. normalidad, que se refleja en la eficiencia glótica. Conclusión: Los parámetros vocales se mostraron alterados en los casos clínicos reportados con SAR-CoV-2, y es importante que los profesionales de la salud también sean conscientes de esta posibilidad de identificación y acción terapéutica para que, con un aumento en el número de analistas, se puede discutir si los cambios vocales se pueden incluir o no en los protocolos de identificación y rehabilitación de la COVID-19.

Palabras clave: Infecciones por Coronavirus; COVID-19; Virus del SRAS; Voz; Fonoaudiología.

\section{Introdução}

A infecção por um novo vírus, o coronavírus (SARS-CoV-2) teve início em uma megacidade central da China, em Wuhan, em 2019 (Cohen \&Normile,2020) e foi disseminado pelo mundo ameaçando tanto a saúde quanto a economia internacional (Anderson et al.2020; Zhang \& Liu, 2020), acarretando em mortes (Anderson et al.2020). Em 16 de abril de 2020, de acordo com a Organização Mundial da Saúde (World Health Organization, 2020a), havia no mundo aproximadamente 2 milhões de pessoas com o diagnóstico confirmado da doença, com 130.885 mortes, com maiores impactos na China, na Europa e no Mediterrâneo Oriental (em especial, o sudoeste da Ásia, onde localiza-se o Irã), com aumento dos infectados nas Américas. A doença causada pelo novo coronavírus denomina-se Covid-19 (Chen \& Yu, 2020).

Sendo assim, medidas para seu combate são extremamente necessárias. Pesquisas foram desenvolvidas ao longo dos meses e, assim, surgiram as vacinas e tratamentos para mitigar a proliferação do vírus (Forni et al., 2021; Case et al., 2021). Algumas medidas também contribuíram para diminuir o seu impacto, tais como disseminação e uso da etiqueta respiratória; autocuidado físico - como higienização pessoal e do ambiente; cuidados e boas práticas nos ambientes compartilhados (incluindo os alimentares); reorganização dos serviços de atendimento em saúde; distanciamento social; isolamento domiciliar para os infectados, além de leitura constante das recomendações sanitárias (Ministério da Saúde, 2020a). A prevenção e as ações em massa minimizam a contaminação pelo SARS-Cov-2, tendo em vista que a contaminação desse vírus é não linear e caótica (Chen \& Yu, 2020).

Os sintomas comuns no início da doença, de acordo com amostra de 41 sujeitos hospitalizados em Wuhan foram: febre (98\% dos pacientes), tosse seca (76\%) e mialgia ou fadiga (44\%). Os menos comuns foram produção de escarro (28\%), dor de cabeça (8\%), hemoptise (expectoração com sangue, 5\%), diarreia (3\%) e conjuntivite (0,8\%). Aproximadamente a metade da amostra (55\%) desenvolveu dispneia em oito dias e $63 \%$ apresentaram linfopenia. O achado comum a todos os pacientes foi a anormalidade na tomografia computadorizada de tórax. Quanto às complicações do quadro clínico, houve a presença da síndrome do desconforto respiratório agudo (29\%), presença do ácido nucleico sérico de SARS-CoV-2 RNAaemia (15\%), lesão cardíaca aguda (12\%) e infecção secundária (10\%), sendo necessária a internação em unidade de terapia intensiva para $32 \%$ da amostra. O percentual de óbitos foi de 15\% (Huang et al., 2020).

De acordo com a literatura (Chen et al. 2020), a presença da RNAaemia foi confirmada exclusivamente no grupo de 
pacientes críticos, parecendo refletir a gravidade da doença. Além disso, os níveis de citocina inflamatória IL-6 mostraram-se associados à RNAaemia, estando tais níveis significativamente elevados (dez vezes mais do que o normal) em pacientes críticos. Tais resultados possibilitam vislumbrar, nesses pacientes, a resposta inflamatória excessiva, conferindo-lhes um pior prognóstico.

O Ministério da Saúde do Brasil, em 2020, editou um "Protocolo de Manejo do Coronavírus (Covid 19) na Atenção Primária à Saúde" (Ministério da Saúde, 2020b), registrando que os sinais e sintomas da doença incluem febre, tosse, dispneia, mialgia, fadiga, sintomas respiratórios superiores e gastrointestinais.

Pode haver ainda, em casos mais severos, associação do coronavírus com a meningite, sendo relatado caso clínico da infecção com presença, por exame de imagem (tomografia computadorizada), de sinal hiperintenso em ventrículo lateral direito, no lobo temporal mesial direito e hipocampo, evidenciando suas manifestações no sistema nervoso central (Moriguchi et al., 2020).

Como os sintomas do SARS-CoV-2 são similares aos da gripe, que é uma infecção viral aguda das vias respiratórias superiores com a presença de febre, mialgias, cefaleias intensas com fotofobias, tosse seca, astenia, dor de garganta, cansaço e mal-estar geral, muitos casos do SARS-CoV-2 podem ter sido subdiagnosticados. Cabe lembrar ainda que a gripe também pode acarretar em complicações como a bronquite, a pneumonia e, nos casos mais graves, levar à morte (Rosas, 2008).

Nas laringites, gripes, resfriados e processos inflamatórios agudos geralmente há mudanças na voz, caracterizadas por modificações na qualidade vocal (Souza et al., 2011), sendo considerado disfonia quando tais alterações perduram por quinze dias (Behlau, Azevedo \& Pontes, 2001). Nesses casos, o fonoaudiólogo, profissional que atua entre outras áreas, na voz, é responsável pela análise dos parâmetros vocais como a rugosidade, a soprosidade, a tensão, a astenia e a instabilidade vocal por meio da análise acústica ou pela análise perceptivo auditiva vocal considerada a avaliação padrão-ouro em voz (Behlau \& Pontes, 2001).

Em relação aos exames para análise vocal, pesquisadores comentaram que os procedimentos de alto risco de contaminação para os profissionais da saúde são a avaliação clínica e a endoscópica da faringe, da laringe e da deglutição, no qual acrescentaram a possibilidade de haver disfonia e disfagia (Mattei et al., 2020). No período de pandemia, tais exames devem ser realizados em situações emergenciais, atendo-se às medidas de proteção individual e à higienização dos equipamentos (World Health Organization, 2020b; Gutiérrez-Gómez \&Rodríguez-Ruiz, 2020).

Frente ao exposto, a presente pesquisa parte da seguinte questão clínica: "Pacientes com suspeita de infecção ou confirmação de SARS-CoV-2 apresentam alterações vocais?".

Desta forma, o objetivo da presente pesquisa foi descrever as alterações vocais produzidas pela síndrome gripal ocasionada pelo SARS-CoV-2 (casos confirmados e suspeito).

\section{Metodologia}

Estudo retrospectivo, transversal e constituído por amostra de conveniência em que os participantes consentiram na disponibilização de amostras de voz para a presente pesquisa. A pesquisa foi aprovada pelo Comitê de Ética em Pesquisa sob o número CAAE 31385120.8.0000.5546 (Parecer No 4.048.414).

A amostra foi constituída por quatro casos clínicos (um com diagnóstico clínico epidemiológico e outros três com diagnóstico laboratorial confirmado de COVID-19 tanto na testagem como na retestagem), de sujeitos entre 56 e 81 anos de vida, sendo três do sexo feminino e um do masculino, três residentes em São Paulo/Brasil e um em Aracaju/Brasil, porém de férias em São Paulo, todos adquiriram Covid-19 por meio de transmissão comunitária.

A captura das amostras de voz foi obtida por meio de aplicativo de mídia social Whatsapp, no qual foram solicitadas a gravação em dois momentos: o primeiro, com quadro agravado da síndrome gripal (ou seja, no início da manifestação clínica 
da COVID-19) e o segundo, em momento de alta hospitalar ou diminuição dos sinais e sintomas do quadro clínico. Este recurso de captura das amostras vocais foi utilizado tendo em vista a impossibilidade de visita hospitalar aos sujeitos da pesquisa mediante necessidade de isolamento social devido à pandemia da Covid-19 (Ministério da Saúde, 2020a).

Para a análise dos parâmetros vocais optou-se pela avaliação perceptivo-auditiva dos seguintes parâmetros vocais: pitch, loudness, ressonância, ataque vocal, coordenação pneumofonoarticulatória e tipo de voz.

A avaliação perceptivo-auditiva foi realizada seguindo as contextualizações sugeridas pela literatura (Pinho, 2003):

- O pitch, que é a percepção subjetiva da frequência habitual da fala, sendo considerado adequado quando houve congruência entre o biotipo, idade e sexo; grave, quando a percepção subjetiva de frequência vocal foi mais baixa relacionada ao biotipo, idade e sexo, agudo, quando a percepção subjetiva de frequência vocal foi mais alta relacionada ao biotipo, idade e sexo e adequada quando a percepção subjetiva de frequência vocal foi compatível com biotipo, idade e sexo. De forma complementar, além de julgar se o pitch se encontra adequado, grave ou agudo para a idade e sexo, optou-se por verificar a severidade da alteração em grau leve, moderado e severo.

- A loudness se refere a sensação psicofísica relacionada à intensidade, ou seja, fraca, adequada ou forte. Tem relação direta com a fisiologia das pregas vocais, sua coaptação glótica, bem como com a capacidade respiratória do indivíduo.

- A ressonância vocal foi classificada como equilibrada, na evidência da distribuição equilibrada entre os principais focos de ressonância (laringe, oral e nasal); laringofaríngea, quando houve predomínio da ressonância mais baixa; a hipernasal, quando houve predomínio da ressonância nasal e hiponasal, quando houve diminuição do uso da ressonância nasal e consequente abafamento do som;

- O ataque vocal, que é a forma que se inicia a fonação, relacionado à configuração glótica da emissão, foi classificado como suave, normal, equilibrado ou isocrônico, sem tensão; brusco, quando a fonação foi caracterizada por início brusco, com tensão e; aspirada ou soprosa, quando na fonação o escape de ar for audível, com fechamento glótico insuficiente e;

- A coordenação pneumofonoarticulatória, que é a relação entre a respiração e a fonação, foi avaliada como adequada quando a relação foi harmônica e inadequada ou incoordenada, quando houve desequilíbrio entre a respiração e a fonação.

Para a avaliação da qualidade vocal foi utilizada a escala perceptivo-auditiva vocal, GIRBAS - Grade, Roughness, Breathiness, Asteny, Strain and Instability, de acordo com Hirano (Hirano, 1981) e adaptada por Dejonckere et al. (1996), por ser considerado o padrão ouro na avaliação da voz. Na tradução para o português brasileiro, o "G" corresponde ao grau geral de alteração encontrada; o "R" à rugosidade ou rouquidão, o "B" à soprosidade, o "A" à astenia, o "S" à tensão e o "I" à instabilidade.

No presente estudo optou-se em avaliar os parâmetros pertencentes a rugosidade, ou seja, rouquidão, crepitação, bitonalidade e aspereza. Para classificar a qualidade vocal de cada item foi utilizada escala numérica de zero a três, sendo zero atribuído na inexistência de alteração vocal, um, quando foi percebida alteração leve, dois para moderada e três para severa, como sugerida pela escala GIRBAS.

As amostras das vozes foram analisadas por três juízes, fonoaudiólogos, com experiência mínima na área de dez anos e especialistas em voz. Foi solicitada a utilização de fones de ouvido, ouvir as gravações sempre na mesma intensidade e avaliar os parâmetros vocais sempre na mesma ordem do protocolo de registro de dados.

Os dados apresentados pelos juízes foram tabulados no software Excel da Microsoft ${ }^{\circledR}$ Office e optou-se pela atribuição do valor de maior concordância entre os juízes ou, na evidência de discordância, o valor atribuído pelo juiz com maior experiência profissional na área. Cabe salientar que as amostras das vozes foram entregues aos juízes de forma cega, ou seja, tanto sem a identificação dos sujeitos participantes da pesquisa quanto do momento da sua gravação - de forma aleatória, conforme sugerido pela literatura (Ribeiro, 2017; Bello, 2018). 


\section{Resultados}

Caso clínico um - paciente procurou pelo teleatendimento de um hospital privado do interior do estado de São Paulo com queixas sugestivas de contaminação por SARS-CoV-2, fazendo uso de dipirona sódica para controlar quadro febril. Em seu relato, explicou que teve contato nos três dias anteriores com seus pais (S2 e S3), que também estavam com os mesmos sintomas. Foi orientada a procurar pelo serviço de emergência com uso de máscara caso a febre aumentasse ou não cedesse, se tivesse piora da tosse ou do quadro de dispneia. Não houve necessidade dessa procura, pois não apresentou mais febre, porém a tosse permaneceu por dez dias, de forma esporádica e houve perda total de olfato e paladar, restaurados paulatinamente a partir do $15^{\circ}$ dia após os primeiros sintomas. Houve relato de presença de pigarro, esporádico, até o final de um mês após os primeiros sintomas, com queixa de cefaleia diária por 32 dias, bem como irritação ocular leve (caracterizada por coceira e vermelhidão), que surgiu após dias dos primeiros sintomas, não sabendo relatar o período com precisão. Cabe ressaltar que S1 negou distúrbios metabólicos, tabagismo e etilismo, porém faz uso profissional da voz por ser docente.

Caso clínico dois - paciente casado com S3 e pai de S1, hipertenso, ex-fumante (histórico de DPOC) e etilista, com histórico de aneurisma de aorta abdominal, iniciou os primeiros sintomas de contaminação pelo SARS-CoV-2 após viagem ao interior do Paraná (Arapongas) para o enterro de sua irmã, situação em que houve aglomeração de pessoas, incluindo uma sobrinha com queixa de dores no corpo, tosse seca e estado subfebril, sem queixas vocais. Ao entrar em contato com o teleatendimento de um hospital militar, recebeu as mesmas orientações de S1. No quarto dia ao fazer uso de dipirona sódica sem cessar quadro febril, piora da dispneia e sensação de fadiga intensa, procurou pelo setor de emergência conforme orientado. Na estratificação da gravidade do quadro e após constatação, pela tomografia pulmonar de vidro fosco e opacidade e saturação de 93\%, foi configurado um quadro de pneumonia e síndrome da angústia respiratória aguda (SARA), a decisão foi de encaminhamento para hospital conveniado. Foi transportado de ambulância e permaneceu internado por dez dias sendo utilizados diversos antibióticos até que a febre cedesse. Alguns dos medicamentos ministrados foram: fosfato de oseltamivir, ceftriaxona, azitromicina e piperacilina. Relatou inapetência durante e após a hospitalização, que durou até a melhora do olfato e do paladar, que ocorreu aproximadamente após quinze dias de sua alta. Na alta, recebeu o diagnóstico positivo do COVID19. Paciente também relatou presença de pigarro pelo período de um mês após os primeiros sintomas.

Caso clínico três - paciente casada com S2 e mãe de S1, hipertensa, ex-fumante, diabética e após dois dias da viagem para o interior do Paraná com o seu esposo S2, começou a apresentar tosse seca e mialgia. Quando seu esposo apresentou piora do quadro, também foi avaliada pela atenção especializada, porém, como saturação estava com $96 \%$ e o quadro estável, indicaram dipirona para diminuir a febre e quarentena de 14 dias em seu domicílio. Dez dias após os primeiros sintomas, o quadro piorou (mialgia, desconforto respiratório, dispneia) e inapetência por perda de olfato e paladar, recusando-se a procurar o hospital. No $14^{\circ}$ dia, ao apresentar-se letárgica e com manifestações gastrointestinais, foi levada à emergência, sendo constatada desregulação metabólica (hipertensão: 22x11, glicose alta: 224), saturação de $89 \%$ e febre de $37,9^{\circ} \mathrm{C}$. A tomografia pulmonar revelou imagem de vidro fosco e opacidade, pneumonia, sendo encaminhada, por ambulância, para a UTI. Permaneceu nessa unidade por três dias com uso de oxigenioterapia, sendo encaminhada para um quarto, em andar isolado para o atendimento de pacientes com Covid-19 - lá permanecendo por mais seis dias. Foi medicada com hidroxicloroquina, azitromicina, lozartana potássica, floratil, aradois e cloridrato de metformina. Na alta hospitalar recebeu a confirmação do diagnóstico de COVID-19. Houve restauração do olfato e do paladar após dezenove dias, segundo relato. Negou etilismo.

Caso clínico quatro - paciente do sexo feminino (S4), manifestou seus primeiros sintomas após dezesseis dias do falecimento de seu pai, 84 anos, por pneumonia. Procurou hospital particular com queixa de febre baixa que não cessava mesmo com uso de dipirona sódica. Ficou internada por onze dias, com uso oxigenioterapia e uso de medicamentos tais como fosfato de oseltamivir, hidroxicloroquina e azitromicina, recebendo o diagnóstico confirmado de COVID-19. Olfato e paladar recuperados dezoito dias após a internação, porém ainda persiste a presença do pigarro (33 dias após a internação), de forma 
esporádica. A cefaleia, que pelo relato era diária e intensa, cessou com 24 dias após a internação. Negou tabagismo e etilismo e acrescentou que faz uso da voz profissionalmente por ser relações públicas.

No Quadro 1 constam os dados sociodemográficos e as queixas iniciais da amostra selecionada e a Tabela 1 apresenta os resultados obtidos na Escala GIRBAS, no qual observa-se que todos os pacientes apresentaram alteração no grau geral da disfonia no momento durante a manifestação clínica da doença e apenas um sujeito não apresentou diminuição no grau de severidade no final da doença.

Quadro 1. Dados sociodemográficos da amostra selecionada e os sintomas iniciais do SARS-CoV-2.

\begin{tabular}{|c|c|c|c|c|c|c|c|c|}
\hline \multirow{2}{*}{ Sujeito No } & & & & \multicolumn{3}{|c|}{ Queixas Iniciais do SARS-CoV-2 } \\
\cline { 5 - 8 } & Gênero & Idade & Localidade & Tosse Seca & $\begin{array}{c}\text { Febre ou } \\
\text { estado } \\
\text { Subfebril }\end{array}$ & Cefaleia & $\begin{array}{c}\text { Queixas } \\
\text { vocais }\end{array}$ & $\begin{array}{c}\text { Ageusia } \\
\text { e/ou } \\
\text { Anosmia }\end{array}$ \\
\hline 1 & Feminino & 56 & Aracaju/SE & Sim & Sim & Sim & $\begin{array}{c}\text { Cansaço ao } \\
\text { falar }\end{array}$ & Sim \\
\hline 2 & Masculino & 81 & São Paulo/SP & Sim & Sim & Não & Não & Sim \\
\hline 3 & Feminino & 79 & São Paulo/SP & Sim & Sim & Não & Sim \\
\hline 4 & Feminino & 57 & São Paulo/SP & Sim & Sim & Sim & Dispneia & Sim \\
\hline
\end{tabular}

Fonte: Autores.

Tabela 1. Resultados da avaliação perceptivo-auditiva vocal pela escala GIRBAS dos sujeitos avaliados durante e após o Covid-19.

\begin{tabular}{|c|c|c|c|c|c|c|c|c|c|c|}
\hline \multirow{2}{*}{\multicolumn{2}{|c|}{$\begin{array}{c}\text { Parâmetros } \\
\text { analisados / } \\
\text { Sujeitos }\end{array}$}} & & \multicolumn{4}{|c|}{ Durante a infecção } & \multicolumn{4}{|c|}{ Pós-infecção } \\
\hline & & & S1 & S2 & $\mathbf{S 3}$ & S4 & S1 & S2 & S3 & S4 \\
\hline \multirow{9}{*}{ GIRBAS } & Grau Geral & & 1 & 2 & 1 & 2 & 0 & 1 & 1 & 1 \\
\hline & \multirow{4}{*}{ Rugosidade } & $\mathrm{R}$ & 1 & 0 & 1 & 2 & 0 & 0 & 0 & 1 \\
\hline & & $\mathrm{C}$ & 0 & 0 & 0 & 2 & 0 & 0 & 0 & 0 \\
\hline & & $\mathrm{B}$ & 1 & 0 & 1 & 1 & 0 & 1 & 1 & 0 \\
\hline & & A & 0 & 0 & 1 & 1 & 0 & 0 & 0 & 0 \\
\hline & Soprosidade & & 1 & 2 & 1 & 1 & 0 & 1 & 0 & 1 \\
\hline & Astenia & & 0 & 1 & 1 & 1 & 0 & 0 & 0 & 0 \\
\hline & Tensão & & 0 & 0 & 0 & 1 & 0 & 0 & 0 & 0 \\
\hline & Instabilidade & & 0 & 0 & 1 & 1 & 0 & 0 & 0 & 0 \\
\hline
\end{tabular}

Legenda: A: aspereza; B: bitonalidade; C: crepitação e R: rouquidão. Fonte: Autores.

Por meio da Tabela 2 é possível observar que, exceto o ataque vocal, todos os parâmetros vocais avaliados apresentaram alteração no momento durante a manifestação clínica da COVID-19. 
Tabela 2. Resultados da avaliação perceptivo-auditiva vocal dos sujeitos avaliados durante e após o Covid-19.

\begin{tabular}{|c|c|c|c|c|c|c|c|c|}
\hline \multirow{2}{*}{$\begin{array}{c}\text { Parâmetros } \\
\text { analisados / } \\
\text { Sujeitos }\end{array}$} & \multicolumn{4}{|c|}{ Durante a infecção } & \multicolumn{4}{|c|}{ Pós-infecção } \\
\hline & S 1 & $\mathbf{S 2}$ & S3 & S4 & S1 & $\mathbf{S 2}$ & S3 & S4 \\
\hline Pitch & grave leve & grave leve & grave leve & $\begin{array}{c}\text { grave } \\
\text { moderado }\end{array}$ & adequado & adequado & grave leve & grave leve \\
\hline Ressonância & $\begin{array}{c}\mathrm{Rd} \\
\text { moderada }\end{array}$ & $\begin{array}{c}\mathrm{Rd} \\
\text { moderada }\end{array}$ & $\begin{array}{c}\mathrm{Rd} \\
\text { moderada }\end{array}$ & $\mathrm{R}$-LGF & equilibrada & Rd leve & Rd leve & Rd leve \\
\hline CPFA & I -leve & $\begin{array}{c}\text { I- } \\
\text { moderada }\end{array}$ & $\begin{array}{c}\text { I- } \\
\text { moderada }\end{array}$ & I -leve & adequado & adequado & I -leve & adequado \\
\hline Loudness & fraco & fraco & fraco & fraco & adequado & adequado & adequado & adequado \\
\hline Ataque Vocal & adequado & adequado & adequado & adequado & adequado & adequado & adequado & adequado \\
\hline
\end{tabular}

\section{Discussão}

Ocorreram mundialmente seis emergências em saúde, a saber: a pandemia do H1N1 em 2009, de poliovírus e de ebola em 2014 (este último com nova emergência em 2018), do zikavirus em 2016 e em 2019 do novo coronavírus (Organização Panamericana de Saúde, 2020).

Em relação a esse último vírus, suspeitou-se que o início da infecção tenha ocorrido pelo contato direto com animais hospedeiros intermediários (como as tartarugas e os pangolins) ou pelo consumo de animais selvagens, como os morcegos, embora a rota de transmissão do SARS-CoV-2 ainda permaneça inconclusiva (Guo et al., 2020).

O curso clínico do Covid-19 parece semelhante ao do H1N1, embora os agentes infecciosos sejam distintos, apresentam formas de transmissibilidade e sintomas similares. Ainda assim, o SARS-CoV-2 apresentou, em três meses, o mesmo número de letalidade que o H1N1 no Brasil (Egypto Teixeira et al., 2020).

Em onze de fevereiro de 2020, o Centro Chinês de Controle e Prevenção de Doenças relatou o maior estudo mundial de série de casos, com a quantidade de 72.314 casos da Covid-19, destes $62 \%$ com casos confirmados e os demais percentuais divididos entre suspeitos, em diagnóstico e assintomáticos. O estudo revelou que a maioria dos infectados apresentavam faixa etária entre 30 e 79 anos (87\% dos casos), com grau de severidade leve (81\%), além de indicar que as letalidades ocorreram, com maior prevalência, naqueles sujeitos que apresentavam comorbidades pré-existentes (como as doenças metabólicas, respiratórias, cardíacas e oncológicas, por exemplo) (Wu \& Mcgoogan, 2020). Os resultados do estudo são similares a este em relação à idade (média: 68,25 anos) e quanto ao grau de severidade, sendo que os casos de S2 a S4 necessitaram internação, mas não de intubação e apenas S1 não necessitou de cuidados hospitalares (Wu \& Mcgoogan, 2020).

Os sinais e sintomas mais comuns na Covid-19, bem como as manifestações gastrointestinais (relatados pela minoria) dos casos relatados neste estudo foram similares aos de pesquisadores (Huang et al., 2020), embora tenha havido maiores queixas quanto à produção de pigarro (relatados por S1, S2 e S4) em contrapartida aos $28 \%$ descritos pelos autores e da cefaleia que foi relatada por S1 e S4 de longa duração, contrastando com os $8 \%$ citados pelos autores. Outra manifestação de longa duração e que foi queixa de todos os pacientes deste estudo foi a anosmia súbita associada à ageusia. Pesquisadores (Vaira et al., 2020) relataram que um número significativo de pacientes por eles atendidos apresentaram anosmia e ageusia associados à febre como sintomas iniciais da Covid-19, sendo que em alguns casos, estas manifestações foram as únicas da doença e, por este motivo, o caso de S1, mesmo que não tenha havido a confirmação da doença, foi incluído na amostra. 
Entretanto, em um outro estudo os pesquisadores relataram percentual baixo dessas manifestações (hiponosmia em 5,1\% e hipogeusia em 5,6\% dos casos) (Mao et al., 2020)

Cabe salientar que Mao et al. (2020) dividiram os sintomas dos pacientes com Covid-19 em três categorias: a primeira, relacionada ao sistema nervoso central (como as cefaleias, o zumbido, o prejuízo na consciência, a ataxia, o acidente vascular encefálico agudo e epilepsia); a segunda, ao sistema nervoso periférico (hipogeusia, hiposmia e neuralgia) e a terceira, as musculoesqueléticas. Relataram manifestações neurológicas em 36,4\% dos pacientes, acrescentando que esses sinais e sintomas ocorreram em quadros mais severos. Transpondo para a amostra do presente estudo, teríamos tais sinais e sintomas em S1 e S4. A anorexia citada pelos autores, em 31,8\%, esteve presente em S2 e S3 e a diarreia em 19,2\% dos casos do estudo supramencionado, que nesta série de casos, ocorreu apenas em S3. Já em relação aos sintomas musculoesqueléticos, no estudo de Mao et al. (2020), o percentual foi 10,7\% da amostra, enquanto esta foi uma queixa comum neste estudo, presente em S2, S3 e S4. Por ser este, um estudo exploratório, tais divergências são esperadas e, apenas com amostras maiores é que as queixas podem ser um indicativo da gravidade da doença.

Teorias têm sido elencadas em relação à inoculação direta dos tecidos oculares pelo SARS-CoV-2, uma vez que nos animais hospedeiros pode ocasionar irritação ocular, conjuntivite, uveíte anterior, retinite ou neurite óptica. Sendo assim, as implicações oculares na Covid-19 não podem ser ignoradas (Seah \& Agrawal, 2020). O acometimento oftalmológico foi observado em 31,6\% da amostra, ou seja, em 1/3 dos pacientes com COVID-19 (Wu et al., 2020) - ratificando os dados do nosso estudo, em que o envolvimento ocorreu apenas em S1. Salientaram ainda que apesar da baixa prevalência do SARSCoV-2 na lágrima, há a possibilidade de sua transmissão pelos olhos.

O Conselho Federal de Fonoaudiologia brasileiro (Conselho Federal de Fonoaudiologia, 2020), ao considerar que o atendimento fonoaudiológico requer contato direto entre paciente e terapeuta favorecendo, portanto, o risco de contágio do Covid-19, resolveu suspender os atendimentos ambulatoriais, bem como os procedimentos e exames eletivos. As formas mais comuns de transmissão ocorrem pelo ar e pelo contato pessoal com secreções contaminadas, gotículas de saliva, espirro, tosse, catarro. Por conta desse fato, este estudo foi realizado remotamente, sendo as vozes avaliadas a partir de gravações e enviadas aos juízes por aplicativo de voz dos smartphones. Em nenhum momento houve contato direto entre fonoaudiólogo/pesquisador e paciente, fato que não inviabilizou as análises perceptivo-auditivas das vozes, visto que os áudios estavam com boa qualidade sonora e, portanto, fieis às vozes dos sujeitos.

Observou-se, neste estudo, a presença de alterações vocais durante a infecção, de leve a moderada, em 100\% dos casos analisados. Não foi observada nenhuma alteração severa, provavelmente pela precocidade dos sintomas, pelos quadros clínicos que não necessitaram de intubação orotraqueal e também pela reduzida amostra. Na escala GIRBAS, o grau geral (G) da alteração variou entre 1 e 2, ou seja, leve e moderado, sendo possível observar comprometimentos em alguns dos subitens da escala. No que diz respeito à rugosidade $(\mathrm{R})$, constatou-se: rouquidão leve e moderada, bitonalidade leve em três casos (S1, S3 e S4), aspereza apenas em S3 e S4 e crepitação apenas no sujeito 4. A soprosidade (B) foi observada em todos os casos de leve a moderada. A astenia (A) foi comum nos sujeitos S2, S3 e S4, em uma intensidade discreta. A tensão (S) foi observada apenas no sujeito S4 e a instabilidade (I) em S3 e S4.

O sintoma de rouquidão é o mais comum nos quadros de disfonias decorrentes de alterações de vias aéreas superiores. Em um estudo sobre a ocorrência de sintomas vocais, sua relação e prováveis causas em uma amostra populacional, constatouse relação estatística significante entre rouquidão e afecções respiratórias superiores (Ferreira et al., 2009).

Após a infecção houve remissão da maior parte dos sintomas vocais e redução da severidade de outros. A rouquidão, por exemplo, permaneceu apenas em S4, sujeito que já apresentava alterações vocais antes da infecção por Covid-19. Ainda que presente, a rouquidão diminuiu de intensidade, passando de moderado a discreto. Essa característica é a mais comum manifestação de alteração vocal, representa uma situação em que a vibração das pregas vocais é alterada, por vasodilatação, 
edema ou presença de massa ou muco (Behlau, 2013), comum em episódios de quadros gripais, por exemplo. A diminuição desse sintoma, nos casos aqui estudados, pode ser justificada, então, pela redução do acometimento das pregas vocais após controle da infecção. Pesquisadores (Mattei et al., 2020) reiteram que pode haver disfonia e disfagia em casos de Covid-19, sendo que a terapia vocal não é uma urgência no momento. Além destes fatos, vale considerar que os sujeitos desta pesquisa apresentaram tosse como parte dos sintomas respiratórios, o que em si é capaz de irritar a mucosa das pregas vocais e causar alteração na qualidade vocal.

A crepitação presente apenas em S4 desapareceu após a infecção, bem como a aspereza também não foi mais observada em S3 e S4. Crepitação é caracterizada por tom grave, pequena intensidade, grande aperiodicidade e laringe, provavelmente, com pregas vocais grossas e encurtadas, podendo ou não ocorrer a vibração das pregas vestibulares. Já a aspereza, voz rude, desagradável, com esforço à emissão, é típica de situações de rigidez de mucosa de pregas vocais(Behlau, 2013).

A soprosidade, voz acompanhada de ar não-sonorizado pelas pregas vocais, pode ocorrer por ineficiência no fechamento glótico. Observou-se que esta característica desapareceu em S1 e S3, diminuiu de severidade em S2 e permaneceu igual em S4. A melhora deve-se a recuperação da condição laríngea após a infecção. Sabendo que o tipo de voz carrega ainda elementos das outras duas dimensões, psicológica e socioeducacional (Behlau, 2013), vale considerar que algumas características vocais encontradas nestes indivíduos participantes do estudo, como por exemplo, a tensão e a soprosidade, tenham relação não apenas com as questões anatômicas e mecânicas, mas também com a ansiedade que o diagnóstico da Covid-19 tende a causar. Autores relataram aumento leve de níveis de estresse, ansiedade e depressão em especial na população mais jovem e com enfermidades crônicas, hipotetizando que com o avançar do isolamento social e da Covid-19, possa haver aumento de sintomas psicoemocionais (Ozamiz-Etxebarria et al., 2020).

Observou-se alteração no pitch em todos os casos analisados, com característica de rebaixamento da frequência fundamental, ou seja, pitch grave. Isso pode ocorrer quando as pregas vocais se encontram edemaciadas, fato comum em pacientes com síndromes respiratórias. Após a infecção, observou-se uma adequação do pitch em S1 e S2, diminuição do grau (de moderado a discreto) em S4 e manutenção da característica em S3. O pitch é um atributo que é diferente entre os sexos, sendo nos homens mais grave do que nas mulheres (Felippe et al., 2006), sendo possível concluir que as mudanças neste aspecto podem facilitar a identificação da presença de disfonia mesmo para leigos (Pereira et al., 2018). Pode-se inferir que o pitch reduzido durante a infecção deva ter ocorrido, muito provavelmente, devido ao peso da massa do edema nas mucosas das pregas vocais (Ferreira et al., 2009).

Em $100 \%$ dos casos, a loudness também se mostrou alterada, caracterizada por redução da intensidade da voz, ou seja, voz fraca. A loudness, percepção psicofísica da intensidade, tem relação direta com a fisiologia das pregas vocais, sua coaptação glótica e seu fluxo aéreo respiratório. Portanto quando a capacidade respiratória do indivíduo está comprometida é comum uma diminuição da projeção vocal, ou seja, da intensidade percebida pela redução do fluxo aéreo (Behlau, 2013). Uma ressalva a ser feita diz respeito às limitações quanto à coleta das amostras de áudio, não havendo rigor científico e devendo esta análise ser interpretada com cautela, pois um sujeito pode ter feito a gravação sem distanciamento da fonte enquanto outro pode tê-lo feito, sendo este um viés de análise que deve ser considerado. Este viés foi mantido na análise tendo em vista que outros parâmetros estiveram alterados, como a coordenação pneumofonoarticulatória, visto que esta também é dependente do controle respiratório e do equilíbrio entre ele e a fonação. Os distúrbios pulmonares tendem a modificar a corrente aérea, desestabilizando a relação básica entre as forças aerodinâmicas pulmonares e mioelásticas da laringe, o que pode levar a alterações na coordenação pneumofonoarticulatória, bem como na ressonância (Ferreira et al., 2009).

Em um estudo sobre os achados tomográficos em pacientes brasileiros com Covid-19, observou-se achados pulmonares tanto nos indivíduos sintomáticos quanto nos assintomáticos, sendo a diferença entre os achados limitada apenas 
quanto à extensão do acometimento pulmonar (Chate, 2020). Nos primeiros quatro dias após o início dos sintomas já foi possível observar alterações no exame de imagem dos pulmões e após o $14^{\circ}$ dia teve início a reabsorção das consolidações. A resolução dos achados parece ocorrer, então, após o trigésimo dia, podendo deixar cicatrizes pulmonares, justificando o acompanhamento longitudinal de pacientes que apresentaram Covid-19 por diferentes profissionais da saúde.

Os coronavírus (CoVs) são um grupo de vírus de RNA que podem causar infecções respiratórias e gastrointestinais. A maioria dos pacientes infectados é assintomática ou apresenta sintomas leves a intermediários, podendo evoluir para insuficiência respiratória grave e óbito em uma parcela desta população (Brito \& Silva et al., 2020). Após a infecção, todos os sujeitos do estudo (de S1 a S4) voltaram a apresentar loudness adequada, o que pode ser justificada pela remissão do transtorno respiratório.

Além disso, o quadro comprovado de pneumonia viral de S2, S3 e S4 levaram à uma deficiência respiratória hipoxêmica, gerando necessidade de oxigenioterapia (Silva e Silva et al., 2020), acarretando em menor aporte expiratório e, consequentemente, redução da loudness. Ademais, sabe-se que com o avançar da idade, há mudanças no sistema respiratório, podendo haver diminuição na capacidade respiratória, que pode interferir no tempo máximo de fonação (Carréra et al., 2016), sendo esta uma limitação deste estudo, uma vez que não foi possível a análise desse parâmetro, em especial, nos sujeitos S2 e S3.

Por sua vez, a ressonância, que consiste na distribuição da energia sonora ao longo do trato vocal, necessita da integridade das estruturas responsáveis pelo amortecimento e amplificação de determinados sons na laringe, faringe, cavidade oral e nasal, seios paranasais. Os pacientes com Covid-19 comumente apresentam alterações nasais, decorrentes da presença de secreção e edema da mucosa das vias respiratórias altas. Os casos apresentados neste estudo demonstraram ressonância alterada do tipo hiponasal e laringofaríngea, estando de acordo a literatura (Ferreira et al., 2009), quando referiu que os distúrbios nasais alteram a ressonância e podem também modificar o padrão vibratório das pregas vocais.

Outra análise a ser considerada diz respeito à idade dos sujeitos 2 e 3, tendo em vista que há mudanças anatomofuncionais no decorrer do envelhecimento, repercutindo na queda da frequência fundamental nas mulheres, aumento de shimmer e de medidas de ruído (Spazzapan et al., 2019), podendo haver rouquidão, soprosidade, afonia, fadiga vocal, esforço necessário para melhorar a projeção vocal, redução na extensão vocal, voz trêmula, dificuldade de controlar a intensidade vocal, dor na região da cintura escapular e sensação de queimação, ardor ou corpo estranho na laringe [43]. No entanto, como foram realizadas comparações vocais em dois momentos e resultados distintos, infere-se impacto do SARSCoV-2 nos sujeitos idosos da amostra.

Sabe-se também que as altas demandas vocais podem também incorrer no surgimento das disfonias, que prejudicam a inteligibilidade da mensagem, principalmente se esta for proferida por um professor a seus alunos (Venites et al., 2004), revelando grande preocupação por parte da Fonoaudiologia e da Otorrinolaringologia quanto ao enfoque ocupacional de profissionais que usam a voz como instrumento de trabalho, tendo em vista os prejuízos econômico e produtivo gerados (Ortiz et al., 2004). Um estudo com professores antes e durante a Pandemia do Covid-19 revelou que houve associação positiva da presença do estresse psicoemocional do professor antes da Covid-19 com o aumento dos sintomas vocais (Besser et al., 2020). Neste sentido, acompanhar longitudinalmente S1 e S4 parece-nos pertinente, a fim de propiciar um melhor uso da voz no ambiente de trabalho.

Sabe-se que diversos fatores podem colocar em risco a saúde vocal, dentre os quais as laringites, tão comuns em decorrência de viroses. Desta forma, era de se esperar que o novo coronavírus ou SARS-CoV-2 também afetasse a região laríngea, dado este confirmado por este estudo, evidenciado pelos sinais e sintomas descritos pelos pacientes da presente amostra, sendo perceptível que o impacto foi gradual, tendo em vista que, na medida em que os pacientes melhoravam, era visível tal melhora também pela produção vocal. Ademais, o funcionamento da voz não depende apenas da coaptação e 
vibração das pregas vocais, estando diretamente ligada a outras estruturas como: musculatura do tórax, pulmão, diafragma, faringe, cavidades oral e nasal. A voz humana e seu funcionamento são complexos e dependem de uma série de fatores para seu funcionamento normotrófico, demonstrando estar afetado nas infecções por SARS-Cov-2.

Foi encontrado um estudo na literatura sobre o impacto do SARS-CoV-2 na voz, sendo este multicêntrico e interinstitucional (Bélgica, Canadá, Espanha, França, Itália, Suiça e a COVID-19 Task Force of the Young-Otolaryngologists of the International Federations of Oto-rhinolaryngological Societies), em que os dados epidemiológicos e clínicos de 702 pacientes com mild-to-moderate COVID-19 foram analisados, por meio de um questionário, sendo constatada a presença da disfonia em 26,8\% dos casos (188 sujeitos), sendo a disfonia mais prevalente nas mulheres e no grupo de fumantes, sendo que houve piora do quadro vocal quando presentes outras comorbidades como a disfagia e a tosse (Lechien et al., 2020). Os autores concluem que a disfonia pode ser um dos sinais da infecção, ratificando o exposto neste estudo. Supomos ainda que os autores encontrariam maior número de sujeitos com alterações vocais caso tivesse sido realizada a análise perceptivo-auditiva vocal, pois muitos pacientes não percebem mudanças em sua voz quando estas são sutis, como as observadas neste estudo (como em S1 e S3 no momento da infecção e em todos os sujeitos da amostra no momento após a infecção).

O presente estudo apresenta algumas limitações como o baixo número de casos clínicos, coleta das emissões vocais sem equipamento específico e ausência de encontro entre os juízes para calibração auditiva. Entretanto, estes entraves são justificáveis pelo momento atual da Pandemia e a dificuldade de encontros presenciais.

\section{Conclusão}

Os parâmetros vocais demonstraram-se alterados nos sujeitos deste estudo durante a manifestação clínica pelo SARCoV-2, sendo importante que os profissionais da saúde fiquem atentos também à essa possibilidade para identificação e para atuação terapêutica especialmente fonoaudiológica, de forma que, com amostras maiores possa ser discutido se as alterações vocais podem ou não ser inseridas nos protocolos de identificação e reabilitação da COVID-19. Assim, sugerem-se pesquisas futuras com um tamanho amostral representativo da população, coleta com equipamentos específicos para gravação das vozes e que sejam realizados também exames laríngeos dos participantes.

\section{Agradecimentos}

Aos pacientes que autorizaram a análise de suas vozes.

\section{Referências}

Anderson, R. M., Heesterbeek, H., Klinkenberg, D., \& Hollingsworth, T. D. (2020). How will country-based mitigation measures influence the course of the COVID-19 epidemic? The Lancet, 395, 931-934. https://doi.org/10.1016/S0140-6736(20)30567-5.

Behlau, M. S. (2013). Voz, o livro do especialista, 2. Revinter.

Behlau, M. S., Azevedo, R. \& Pontes, P. (2001). Conceito de voz normal e classificação das disfonias, In: Behlau, M. S. (Org.), Voz: o livro do especialista. 1, (56-84). Revinter.

Behlau, M. S., Madazio, G., Feijó, D. \& Pontes, P. (2001). Avaliação de voz, In: Behlau, M. S. (Org.), Voz: o livro do especialista. 1, (85-246). Revinter.

Bello, J. Z. (2018). Escala de sintomas vocais pré e pós terapia fonoaudiológica em pacientes disfônicos [Dissertação de Mestrado]. Universidade Federal de Ciências da Saúde]. https://repositorio.ufcspa.edu.br/jspui/handle/123456789/723.

Besser, A., Lotem, S. \& Zeigler-Hill, V. (2020). Psychological stress and vocal symptoms among University Professors in Israel: implications of the shift to online synchronous teaching during the COVID-19 pandemic. J. Voice. https://doi.org/10.1016/j.jvoice.2020.05.028.

Brito, W. G. F. \& Silva, J. P. D. O. (2020). Neuropathological impacts of COVID-19. Braz. J. H. Rev, 3, 4227-4235. https://dx.doi.org/10.34119/bjhrv3n3026.

Carréra, C. M. D., Araujo, A. N. B. \& Lucena, J. A. (2016). Correlation between slow vital capacity and the maximum phonation time in elderly. Rev. CEFAC, 18, 1389-1394. https://doi.org/10.1590/1982-021620161860616. 
Case, J. B., Winkler, E. S., Errico, J. M., \& Diamond, M. S. On the road to ending the COVID-19 pandemic: Are we there yet? Virology, 557, 70-85. https://doi: 10.1016/j.virol.2021.02.003.

Chate, R. C., Fonseca, E. K. U. N., Passos, R. B. D., Teles, G. B. S., Shoji, H. \& Szarf, G. (2020). Presentation of pulmonary infection on CT in COVID-19: initial experience in Brazil. J Bras Pneumol, 46. https://dx.doi.org/10.36416/1806-3756/e20200121.

Chen, X., \& Yu, B. (2020). First two months of the 2019 coronavírus disease (COVID-19) epidemic in China: real-time surveillance and evaluation with a second derivative model. Glob Health Res Policy, 5, 7. https://doi.org/10.1186/s41256-020-00137-4.

Chen, X., Zhao, B., Qu, Y., Chen, Y., Xiong, J., Feng, Y., Men, D., Huang, Q. et al. (2020). Detectable serum SARS-CoV-2 viral load (RNAaemia) is closely associated with drastically elevated interleukin 6 (IL-6) level in critically ill with coronavirus disease. Clinical Infectious Diseases, 71, 1937-1942. https://doi.org/10.1093/cid/ciaa449.

Cohen, J., \& Normile, D. (2020). New SARS-like virus in China triggers alarm. Science, 367(6475), 234-235. https://doi.org/10.1126/science.367.6475.234.

Conselho Federal de Fonoaudiologia (2020). Recomendação n 19 de 19 de março de 2020, que dispõe sobre orientações aos fonoaudiólogos para atuação profissional durante a quarentena em curso, Brasília, CFFa. https://www.fonoaudiologia.org.br/resolucoes/

Dejonckere, P. H., Remacle, M., Fresnel-Elbaz, E., Woisard, V., CrevierBuchman, L. \& Millet, B. (1996). Differentiated perceptual evaluation of pathological voice quality: reliability and correlations with acoustic measurements. Rev Laryngol Otol Rhinol. 117(3), $219-224$.

Egypto Teixeira, C. M., Madruga, G. A. M., Medeiros, G. B. S., Leite Filho, J. G. T. M. \& Duarte, S. S. M. (2020). Análise comparativa das pandemias COVID-19 e H1N1, Braz. J. Hea. Rev., 3, 3591-3595. https://doi.org/10.34119/bjhrv3n2-188.

Felippe, A. C. N., Grillo, M. H. M. M. \& Grechi, T. H. (2006). Normatização de medidas acústicas para vozes normais. Rev. Bras. Otorrinolaringol. 72, 659664. https://doi.org/10.1590/S0034-72992006000500013.

Ferreira, L. P. Santos, J. G. \& Lima, M. F. B. (2009). Sintoma vocal e sua provável causa: levantamento de dados em uma população. Rev. CEFAC, 11, 110118. https://doi.org/10.1590/S1516-18462009000100015.

Forni, G., \& Mantovani, A. (2021). COVID-19 vaccines: where we stand and challenges ahead. Cell Death Differ, 557, 70-85. https://doi: 10.1016 /j.virol.2021.02.003.

Guo, Y.-R., Cao, Q.-D, Hong, Z.-S., Tan, Y.-Y., Chen, S.-D.,Jin, H.-J., Tan, K.-S., Wang, D.-Y. \& Yan, Y. (2020). The origin, transmission and clinical therapies on coronavírus disease 2019 (COVID-19) outbreak-an update on the status. Mil. med. res., 7, 1-10. https://doi.org/10.1186/s40779-020-00240-0.

Gutiérrez-Gómez, E., Rodríguez-Ruiz, M. T. \& Fandiño, L. H. J. (2020). Lineamientos ante el COVID-19 para la práctica de la otorrinolaringología: procedimientos quirúrgicos y no quirúrgicos. Acta otorrinolaringol. cir. cabeza cuello, 25-31. http://www.revistaacorl.org/index.php/acorl/article/view/477.

Hirano, M. (1981). Clinical examination of voice. Springer Verlag.

Huang, C., Wang, Y., Li, X., Ren, L., Zhao, J., Hu, Y., Zhang, L., Fan, G. et al. (2020). Clinical features of patients infected with 2019 novel coronavírus in Wuhan, China. Lancet, 395, 497-506. https://doi.org/10.1016/S0140-6736(20)30183-5.

Lechien, J. R., Chiesa-Estomba, C. M., Cabaraux, P., Mat, Q., Huet, K., Harmegnies, B., Horoi, M., Bon, S. D. Le et al. (2020). Features of mild-to-moderate COVID-19 patients with dysphonia. J. Voice. https://doi.org/10.1016/j.jvoice.2020.05.012.

Mao, L., Wang, M., Chen, S., He, Q., Chang, J., Hong, C., Zhou, Y., Wang, D. et al. (2020). Neurological manifestations of hospitalized patients with COVID-19 in Wuhan, China: a retrospective case series study. MedRxiv, in press. https://doi.org/10.1101/2020.02.22.20026500.

Mattei, A., Bretèque, B. A. de la., Crestani, S., Crevier-Buchman, L., Galant, C., Hans, S., Julien-Laferrière, A., Lagierf, A. et al, (2020). Guidelines of clinical practice for the management of swallowing disorders and recent dysphonia in the contexte of the COVID-19 pandemic. Eur. ann. otorhinolaryngol. head neck dis, 137, 173-175. https://doi.org/10.1016/j.anorl.2020.04.011.

Ministério da Saúde (2020). Plano de contingência da Fiocruz diante da pandemia da doença pelo SARS-CoV-2 (Covid 19): versão 1.3 de 30 de março de 2020, Brasil, Ministério da Saúde, 2020.

Ministério da Saúde (2020b). Protocolo de manejo do coronavírus (Covid 19) na atenção primária à saúde, versão 7 , Brasília, Ministério da Saúde, 2020. https://www.unasus.gov.br/especial/covid19/profissionais.

Moriguchi, T., Harii, N., Goto, J., Harada, D., Sugawara, H., Takamino, J., Ueno, M, Sakata, H. et al. (2020). A first case of meningitis/encephalitis associated with SARS-Coronavírus-2. Int. j. infect. dis., 34, 55-58. https://doi.org/10.1016/j.ijid.2020.03.062.

Organização Panamericana de Saúde (2020). Brasil, Folha informativa - COVID-19 (doença causada pelo novo coronavírus) O6 de maio de 2020. https://www.paho.org/bra/index.php?option=com_content $\&$ view=article \&id=6101: covid19\&Itemid=875.

Ortiz, E., Costa, E. A., Spina, A. L. \& Crespo, N. (2004). Multidisciplinary protocol proposal for professional dysphonia: preliminary study. Rev. Bras. Otorrinolaringol, 70, 590-596. https://doi.org/10.1590/S0034-72992004000500003.

Ozamiz-Etxebarria, N., Dosil-Santamaria, M., Picaza-Gorrochategui, N. \& Idoiaga-Mondragon, N. (2020). Níveis de estresse, ansiedade e depressão na primeira fase do surto de COVID-19 em uma amostra no norte da Espanha. Cad. saúde pública. 36. http://dx.doi.org/10.1590/0102-311X00054020.

Pereira, A. M., Dassie-Leite, A. P., Pereira, E.C., Cavichiolo, J. B., Rosa, M. O. \& Fugmann, E. A. (2018). Percepção auditiva de juízes leigos quanto ao gênero de mulheres com edema de Reinke. CoDAS, 30. http://dx.doi.org/10.1590/2317-1782/20182017046. 
Pinho, S. M. R. (2003). Avaliação e tratamento da voz, In: Pinho, S. M. R. (Org) Fundamentos em fonoaudiologia: tratando os distúrbios da voz (1-37). Rio de Janeiro, Guanabara-Koogan.

Ribeiro, A. C. C. C. (2017). Desenvolvimento e validação de um protocolo de avaliação perceptivo-auditiva da voz de deficientes auditivos usuários de implante coclear [Tese de doutorado] Universidade de Brasília. Repositório Unb. https://repositorio.unb.br/handle/10482/31678.

Rodrigues, A. L. V., Medeiros, A. M. \& Teixeira, L. C. (2017). Impact of the teacher's voice in the classroom: a literature review. Distúrb. comun. 29, 2-9. http://dx.doi.org/10.23925/2176-2724.2017v29i1p2-9.

Rosas, M. R. (2008). Gripe y resfriado: clínica y tratamento. Offarm, 7(2), 46-51. https://www.elsevier.es/es-revista-offarm-4-pdf-13116051

Seah, I., \& Agrawal, R. (2020). Can the coronavirus disease 2019 (COVID-19) affect the eyes? A review of coronaviruses and ocular implications in humans and animals. Ocul immunol. inflamm, 28, 391-395. https://doi.org/10.1080/09273948.2020.1738501.

Silva e Silva, C. M., Andrade, A. N. Nepomuceno, B., Xavier, D. S., Lima, E., Gonzalez, I., Esquivel, M. S., Novais, M. C. M. et al. (2020). Evidence-based physiotherapy and functionality in adult and pediatric patients with COVID-19. Rev. bras. crescimento desenvolv. hum, 30, 148-155. http://doi.org/10.7322/jhgd.v30.10086.

Souza, C. L., Carvalho, F. M., Araújo, T. M., Reis, E. J. F. B, Lima, V. M. C., \& Porto, L. A. (2011). Factors associated with vocal fold pathologies in teachers. Rev. Saúde Pública, 45, 914-921. http://www.scielo.br/scielo.php?pid=S0034-89102011005000055\&script=sci_arttext\&tlng=pt.

Spazzapan, E. A., Marino, V. C. C., Cardoso, V. M., Berti, L. C. \& Fabron, E. M. G. (2019). Acoustic characteristics of voice in different cycles of life: an integrative literature review. Rev. CEFAC, 21. https://doi.org/10.1590/1982-0216/201921315018.

Vaira, L. A., Salzano, G., Deiana, G., \& De Riu. G. (2020). Anosmia and ageusia: common findings in COVID-19 patients. Laryngoscope, 130 , 1787. https://doi.org/10.1002/lary.28692.

Venites, J. P., Bertachini, L. \& Ramos, L. R. (2004). Atuação fonoaudiológica na presbifonia: a efetividade de uma proposta terapêutica, Pró Fono. 4, 1-8.

World Health Organization (WHO) (2020b). Rational use of personal protective equipment for coronavírus disease (COVID-19): interim guidance, March 19 2020. https://apps.who.int/iris/handle/10665/331215.

World Health Organization (WHO). (2020a). Coronavírus disease 2019 (COVID-19) situation report-87, April 16, 2020. https://www.who.int/emergencies/diseases/novel-coronavírus-2019/situation-reports.

Wu, P., Duan, F., Luo, C., Liu, Q., Qu, X., Liang, L. \& Wu, K. (2020). Characteristics of ocular findings of patients with coronavírus disease 2019 (COVID19) in Hubei Province, China. JAMA ophthalmol, 138, 575-578. https://doi.org/10.1001/jamaophthalmol.2020.1291.

Wu, Z. \& Mcgoogan, J. M. (2020). Characteristics of and important lessons from the coronavírus disease 2019 (COVID-19) outbreak in China: summary of a report of 72314 cases from the Chinese Center for Disease Control and Prevention. Jama, 323, 1239-1242. https://doi: 10.1001/ jama.2020.2648.

Zhang, L., \& Liu, Y. (2020). Potential interventions for novel coronavírus in China: a systemic review. J Med Virol, 92, 479-490. https://doi.org/10.1002/jmv.25707. 